\title{
Efficient and Green Approach for the Esterification of Lignin with Oleic Acid Using Surfactant-combined Microreactors in Water
}

\author{
Liangliang An, ${ }^{\mathrm{a}}$ Chuanling Si, ${ }^{\mathrm{b}}$ Guanhua Wang, ${ }^{\mathrm{b}}$ Cheol Soon Choi, ${ }^{\mathrm{a}}$ Yong Ho Yu, ${ }^{\mathrm{a}}$ \\ Jin Ho Bae, ${ }^{a}$ Soo Min Lee, ${ }^{\mathrm{c}}$ and Yong Sik Kim ${ }^{\mathrm{d}, *}$
}

\begin{abstract}
A green, effective, and feasible reaction for esterification of lignin with oleic acid in water at room temperature was investigated. A surfactantcombined system (p-toluenesulfonic acid/4-dodecylbenzenesulfonic acid) was designed to simultaneously solubilize kraft lignin and disperse the oleic acid, producing microreactors for esterification. Esterification using a higher 4-dodecylbenzenesulfonic acid dosage at room temperature was found to be a good option, and an increasing oleic acid dosage had no effect on improving the degree of esterification. Structural characterization analyses confirmed the successful esterification of lignin with oleic acid, indicating the effectiveness and feasibility of esterification of macromolecules in water. Due to the introduction of a long flexible aliphatic chain, the lignin ester showed a noticeable decrease in glass transition temperature, an obvious increase in contact angle, and exhibited excellent thermoplasticity, processability, and hydrophobicity. Additionally, ligninester nanoparticles were prepared through the micellization of $\mathrm{p}$ toluenesulfonic acid. Therefore, the method of esterification using surfactant-combined microreactors in water is promising for high valueadded utilization of lignin.
\end{abstract}

Keywords: Green reaction; Water; Lignin esterification; Surfactant; Microreactors

Contact information: a: Department of Paper Science \& Engineering, College of Forest and Environmental Sciences, Kangwon National University, Chuncheon 24341, Republic of Korea; b: Tianjin Key Laboratory of Pulp \& Paper, College of Papermaking Science and Technology, Tianjin University of Science \& Technology, Tianjin 300457, China; c: Wood Chemistry Division, National Institute of Forest Science, Seoul 02455, Republic of Korea; d: Division of Forest Material Science \& Engineering, College of Forest and Environmental Sciences, Kangwon National University, Chuncheon 24341, Republic of Korea; *Corresponding author: yongsikk@kangwon.ac.kr

\section{INTRODUCTION}

Ever-increasing rates of petroleum usage, depletion of reserves, and environmental concerns regarding the use of fossil fuels have prompted a need to find alternative renewable resources (Van Dam et al. 2005). Lignocellulose has gained significant attention due to its renewability, wide availability, and lack of competition with food production (Schutyser et al. 2018). Lignocellulosic biomass is primarily composed of cellulose, hemicellulose, and lignin. After cellulose, lignin is the second most abundant natural polymer in the plant kingdom and is the primary renewable source of aromatic structures on Earth. Lignin is an amorphous polymer, composed of three types of phenylpropane units ( $\rho$-coumaryl, coniferyl, and sinapyl alcohols) linked via ether and C-C bonds (Wang et al. 2019). Its high energy, high volume, and attractive structure give it great potential for use 
in bio-based materials. However, currently $<2 \%$ of lignin is commercialized due to several obstacles that require further investigation (Kai et al. 2016).

Chemically, lignin is composed of a variety of functional groups, including hydroxyls (phenolic and aliphatic hydroxyls), methoxyls, carbonyls, and carboxyls (Zhou et al. 2012). The hydroxyl groups, lignin's most characteristic functional groups, possess properties of high reactivity and functional modification flexibility, providing promising polymer preparation potential (Ten et al. 2015).

Esterification of lignin's hydroxyl groups can improve its organic solubility, thermoplasticity, and hydrophobicity (Thielemans and Wool 2005). Hydroxyl esterification leads to decreased hydrogen bonding and increased chain flexibility, which lowers the glass transition point of lignin and improves its processability. Possessing these excellent qualities, esterified lignin has been utilized for various applications (Wang et al. 2016). Its use in polymer blends has been demonstrated by Zhao et al. (2019), in which $15 \%$ lignin ester was blended with poly(vinyl chloride) (PVC) plates and improved the thermal stabilities and mechanical properties of the plates. Luo et al. (2017) reported the synthesis of eight lignin esters that were blended with poly(3-hydroxybutyrate-co-3hydroxyvalerate) (PHBV) or polypropylene (PP), and found that lignin hexanoate showed high thermoplasticity. Further studies have reported lignin ester miscibility with polyethylene (PE) (Dehne et al. 2016), polystyrene (PS) (Pawar et al. 2016), and poly( $\varepsilon$ caprolactone) (PCL) (Teramoto et al. 2009) with improved blend qualities.

Fatty acid esterified lignin has been shown to have remarkably increased non-polar solubility, a considerably reduced glass transition temperature $\left(T_{\mathrm{g}}\right)$, and highly increased hydrophobicity (Lewis et al. 1943; Pawar et al. 2016). Hult et al. (2013) reported that lignin palmitate and laurate derivatives have high potentials as water vapor and oxygen barrier coatings in fiber-based packaging. Gordobil et al. (2017) modified lignin with dodecanoyl chloride, producing a hydrophobic lignin ester for use as a protective agent for wood products. In general, esterification methods are not eco-friendly, using large amounts of organic solvents and hazardous acid anhydride/acyl chloride reagents (Hulin et al. 2015).

Water, as a reaction solvent, has received considerable attention in synthetic organic chemistry due to being low-cost and green. Although an excess of water has been shown to have detrimental effects on the equilibrium of esterification reactions (Manabe and Kobayashi 2002a), a few esterification studies using water have been reported. Baile et al. reported the direct polyesterification of 1,10-decanediol and nonanedioic acid in water using 4-dodecylbenzenesulfonic acid (DBSA) and sodium dodecylbenzenesulfonate catalysts (Baile et al. 1990). Manabe et al. (2002b) also reported a DBSA-catalyzed esterification of lauric acid and 3-phenyl-1-propanol in water. The DBSA acts as a surfactant catalyst, forming emulsion droplets with substrates. The hydrophobic interiors of the droplets exclude water molecules during the reaction. Using this method, a maximum esterification yield of $84 \%$ was obtained. Despite these examples, methods for esterification in water are limited in terms of substrate and reaction applicability. Furthermore, few reports of macromolecular esterification in water exist.

The current work involves the development of surfactant-combined microreactors for the esterification of lignin and oleic acid in water at room temperature. $p$ toluenesulfonic acid (TsOH) and DBSA are used as catalysts for the solubilization and dispersion of lignin and oleic acid, respectively, with the formation of emulsion droplets between the surfactants (TsOH/DBSA) and substrates (lignin/oleic acid). The droplet interiors serve as stable microreactors, whose hydrophobicity excludes water molecules produced during the reaction. The effects of oleic acid dosage, DBSA dosage, and reaction 
temperature on the esterification are discussed. The lignin esters were characterized by gel permeation chromatography (GPC), Fourier-transform infrared spectroscopy (FT-IR), proton nuclear magnetic resonance spectroscopy $\left({ }^{1} \mathrm{H}-\mathrm{NMR}\right)$, particle size analyzer (PSA), thermogravimetric analysis (TGA), differential scanning calorimetry (DSC), and contact angle analysis. Additionally, optical microscopy was used to find evidence related to the hypothetical mechanism of surfactant-combined microreactors formation and the feasibility of esterification in water.

\section{EXPERIMENTAL}

\section{Materials}

Kraft lignin, produced by the kraft pulping of a mixture of various Southeast Asian hardwood chips, was kindly provided by Moorim Pulp \& Paper Co., Ltd. (Ulsan, South Korea). The $p$-toluenesulfonic acid (99\%), 4-dodecylbenzenesulfonic acid (95\%), and oleic acid $(90 \%)$, all analytical grade, were used as received from Sigma-Aldrich (Darmstadt, Germany).

\section{Methods}

\section{Lignin esterification}

A combined-surfactant solution, composed of $40 \% \mathrm{TsOH}$ and a certain amount of DBSA $(0.1 \mathrm{~g}$ or $0.5 \mathrm{~g})$, was prepared in a $250-\mathrm{mL}$ flat-bottomed flask equipped with a magnetic stir bar. Kraft lignin ( $1 \mathrm{~g}$ ) was dissolved in $50 \mathrm{~mL}$ of the solution, followed by dispersal of a certain amount of oleic acid ( $1 \mathrm{~g}$ or $2 \mathrm{~g}$ ), to form an emulsion. The reaction mixture was stirred at reaction temperature for $48 \mathrm{~h}$ at $300 \mathrm{rpm}$. The detailed reaction parameters are shown in Table 1. After the reaction, the mixture was poured into distilled water to precipitate the lignin ester, and purified by dialysis (Cellu-Sep H1, MWCO: 1000; Membrane Filtration Products, Inc., Seguin, TX, USA) to remove excess surfactant and unreacted oleic acid. The waste liquor was concentrated to recycle $\mathrm{TsOH}$ (Fig. 1). After that, the lignin ester was washed with diethyl ether and then dried at $40{ }^{\circ} \mathrm{C}$ for $48 \mathrm{~h}$.

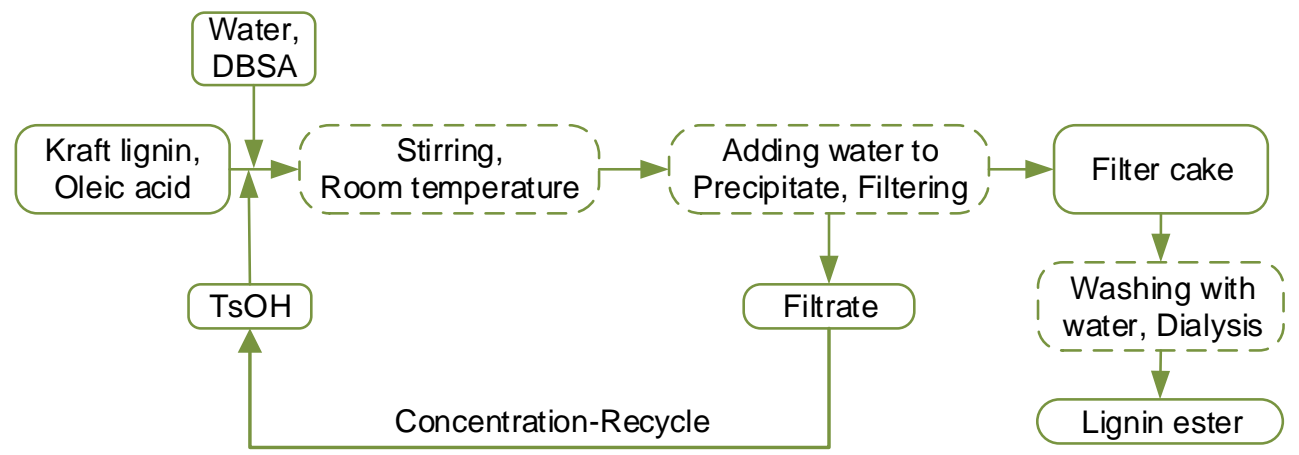

Fig. 1. Schematic flow diagram for esterification of lignin and oleic acid using combined surfactants

\section{Lignin characterization}

FT-IR spectroscopy was conducted using a spectrophotometer (PerkinElmer Frontier, Waltham, MA, USA) with an attenuated total reflectance (ATR) attachment. 
Instrument resolution was $4 \mathrm{~cm}^{-1}$, and a spectrum region of 450 to $4000 \mathrm{~cm}^{-1}$ was used. The FT-IR spectra were obtained directly for lignin samples that had been oven-dried at 40 ${ }^{\circ} \mathrm{C}$ for two days.

The ${ }^{1} \mathrm{H}-\mathrm{NMR}$ spectra were measured using a $600 \mathrm{MHz}$ FT-NMR (Bruker Avance Neo 600; Bruker Corporation, Karlsruhe, Germany). Samples were prepared using $20 \mathrm{mg}$ of lignin dissolved in $0.7 \mathrm{~mL}$ of DMSO- $d_{6}$. Measurements were taken at room temperature using a setting of 128 scans (Wu et al. 2013).

The GPC (Shimadzu-20A; Shimadzu Corporation, Kyoto, Japan), using PLgel columns (PLgel 5- $\mu \mathrm{m}$ mixed-C and -D, and PLgel 3- $\mu \mathrm{m}$ mixed-E), was employed to analyze the average molecular weights of the lignin samples using a previously reported procedure (Seo et al. 2019).

The TGA was performed using an SDT Q600 instrument (TA Instruments, New Castle, DE, USA). A sample heating rate of $20{ }^{\circ} \mathrm{C} / \mathrm{min}$ from 20 to $650{ }^{\circ} \mathrm{C}$ was employed. The sample carrier gas used was $\mathrm{N}_{2}$. The $T_{\mathrm{g}}$ values of the lignin samples were determined using a DSC Q2000 instrument (TA Instruments, New Castle, DE, USA). Approximately 5 to $10 \mathrm{mg}$ lignin samples were used for determination under $\mathrm{N}_{2}$ atmosphere. The temperature program was performed as follows: (1) raise temperature to $105{ }^{\circ} \mathrm{C}$ at a rate of $10{ }^{\circ} \mathrm{C} / \mathrm{min}$, hold for $5 \mathrm{~min}$ to remove moisture, then cool to $20^{\circ} \mathrm{C}$ at a rate of $10{ }^{\circ} \mathrm{C} / \mathrm{min}$; (2) raise the temperature to $180{ }^{\circ} \mathrm{C}$ at a rate of $10{ }^{\circ} \mathrm{C} / \mathrm{min}$; then cool to $20^{\circ} \mathrm{C}$ at a rate of 10 ${ }^{\circ} \mathrm{C} / \mathrm{min}$; (3) raise the temperature to $180{ }^{\circ} \mathrm{C}$ at a rate of $10{ }^{\circ} \mathrm{C} / \mathrm{min}$. The $T_{\mathrm{g}}$ values of the lignin samples were calculated based on the second measurement cycle (Pawar et al. 2016).

Batches of emulsions containing surfactants (TsOH/DBSA) and reactants (lignin/ oleic acid), with the formula: $40 \% \mathrm{TsOH}, 1 \% \mathrm{DBSA}, 2 \%$ lignin, and $2 \%$ oleic acid, were prepared. A second emulsion, with all compounds except oleic acid, was prepared as a control. Samples were then analyzed by optical microscopy (Olympus CKX53; Olympus Corporation, Tokyo, Japan) to determine the mechanism of formation of the surfactantcombined microreactors.

The particle size of the lignin ester was determined using a Malvern Mastersizer 3000 instrument (Malvern Instruments, Ltd., Worcestershire, England). Samples were prepared using the lignin esterification method described earlier, with the dialysis suspension analyzed directly for determination of particle size.

The contact angles of the lignin samples were determined using a contact angle analyzer (Pocket Goniometer, FIBRO System AB; FIBRO Precision Products Co., Ltd., Tranås, Sweden). Lignin samples were prepared by a pressed disc method. Paper tape, with $1 \mathrm{~cm}^{2}$ of double-sided adhesive, was used as the base of the lignin disc. Lignin powder (60 $\mathrm{mg}$ ) was spread flat onto the adhesive, and the lignin disc was pressed to obtain a flat plane. The contact angle was then directly measured from the lignin disc created.

\section{RESULTS AND DISCUSSION}

\section{Formation of Surfactant-combined Microreactors}

In general, for esterification in water to occur, surfactant-type catalysts and substrates need to form emulsion (oil-in-water) droplets. These droplets are stable, and their interiors are hydrophobic, due to the physical interactions of surfactants. During the reaction, carboxylic acids and alcohols undergo esterification in the microreactors formed by the surfactants. Water generated during the reaction is excluded from the droplets, which 
shifts the equilibrium towards products, leading to good yields, despite using water as a solvent (Manabe et al. 2002b).

Although this model is suitable for most low molecular weight carboxylic acids and alcohols, for macromolecules, such as lignin, which have large numbers of reactive hydroxyl groups, dispersion by the same mechanism is difficult. Therefore, a surfactantcombined system (TsOH/DBSA) was designed to form stable emulsion droplets as microreactors for esterification of lignin and oleic acid. First, a high concentration of TsOH was used to solubilize lignin in water. As shown in Fig. 2a, TsOH is a hydrotrope, relying on aggregation for the solubilization of lignin, and can facilitate dissolution of lignin in water to form a clear solution. Optical microscopy showed that lignin was dispersed in the water solution with the aid of $\mathrm{TsOH}$ micelles. Chen et al. (2017) also reported a similar phenomenon for wood lignin dissolved using TsOH micelles. Second, oleic acid was added to the micelle solution using trace amounts of DBSA. As shown in Fig. 2b, lignin and oleic acid were enclosed in the emulsion droplets created by the two surfactants (TsOH/DBSA), forming microreactors.

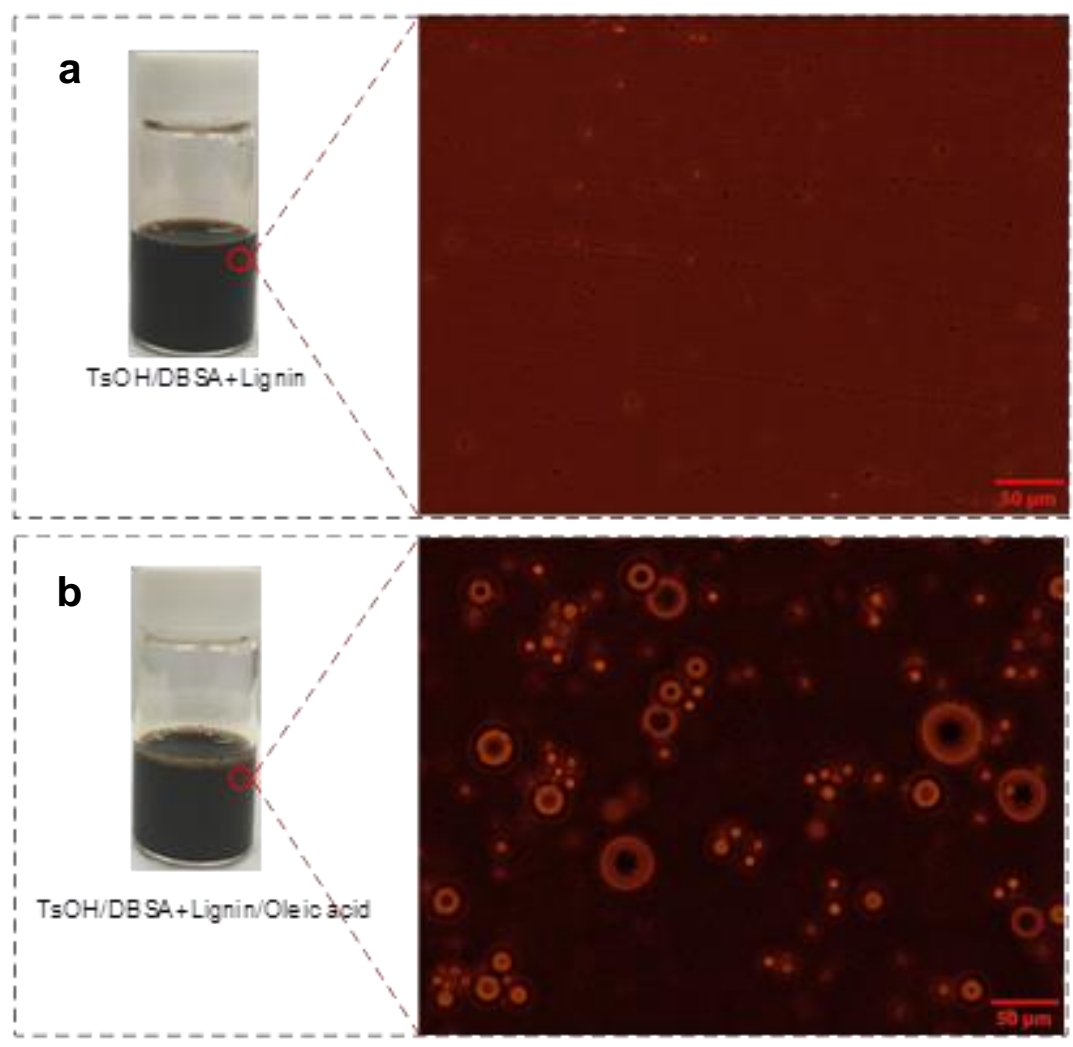

Fig. 2. Microscopic observation of emulsion droplets comprised by $\mathrm{TsOH} / \mathrm{DBSA}$ and lignin/oleic acid

Figure 3 shows a hypothetical model for the esterification of lignin and oleic acid using surfactant-combined microreactors in water based on literature (Manabe et al. 2002). In the interior of the microreactors, lignin and oleic acid are in contact with one another. At the same time, $\mathrm{TsOH}$ catalyzes the esterification reaction by concentrating protons on the surface of the droplets. Water generated during the reaction, which is inhibitory to esterification, is excreted from the microreactors, promoting an equilibrium shift towards products. After the reaction, the concentration of $\mathrm{TsOH}$ is lowered below its critical micelle 
concentration $(\mathrm{CMC})$ by adding water to the reaction mixture. This leads to a decrease in the hydrotropicity of $\mathrm{TsOH}$, and consequently, lignin ester precipitation.

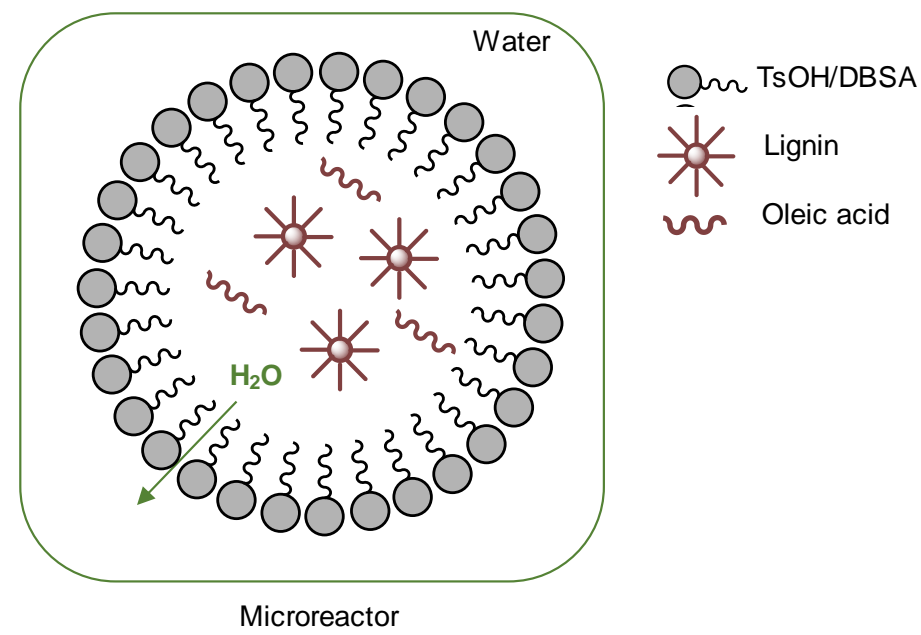

Fig. 3. Hypothetical model of esterification of lignin and oleic acid using surfactant-combined microreactors in water

\section{Molecular Weight and Chemical Structure Analyses of the Lignin Esters}

The effects of oleic acid dosage ( $1 \mathrm{~g}$ or $2 \mathrm{~g})$, DBSA $(0.1 \mathrm{~g}$ or $0.5 \mathrm{~g})$, and reaction temperature $\left(20{ }^{\circ} \mathrm{C}\right.$ or $\left.40{ }^{\circ} \mathrm{C}\right)$ on esterification were analyzed. As shown in Table 1 , the yields of lignin esters were approximately one gram. This may be due to the purification process, as the lignin ester is easily washed away while removing excess oleic acid. Furthermore, using different DBSA dosages, different oleic acid dosage and increasing reaction temperature caused no clear differences in the yield of lignin esters.

Table 1. Yields of Lignin Esters from Different Reaction Parameters

\begin{tabular}{|c|c|c|c|c|c|c|}
\hline Run & $\begin{array}{l}\text { Lignin } \\
\text { (g) }\end{array}$ & Solvent & $\begin{array}{l}\text { Oleic acid } \\
\text { (g) }\end{array}$ & $\begin{array}{c}\text { DBSA } \\
(\mathrm{g})\end{array}$ & $\begin{array}{c}\text { Reaction } \\
\text { temperature } \\
\left({ }^{\circ} \mathrm{C}\right)\end{array}$ & $\begin{array}{c}\text { Yield of } \\
\text { lignin ester } \\
(\mathrm{g})\end{array}$ \\
\hline E1 & \multirow{5}{*}{1} & \multirow{5}{*}{$\begin{array}{c}50 \mathrm{~mL}, 40 \% \\
\mathrm{TsOH}\end{array}$} & 1 & 0.1 & \multirow{4}{*}{$\begin{array}{l}\text { Room } \\
\text { temperature }\end{array}$} & $0.96 \pm 0.22$ \\
\hline E2 & & & 2 & 0.1 & & $0.81 \pm 0.54$ \\
\hline E3 & & & 1 & 0.5 & & $0.94 \pm 0.65$ \\
\hline E4 & & & 2 & 0.5 & & $0.89 \pm 0.34$ \\
\hline E5 & & & 1 & 0.5 & 40 & $0.92 \pm 0.49$ \\
\hline
\end{tabular}

The molecular weight distributions of the kraft lignin and lignin esters were analyzed by GPC. As shown in Fig. 4, an obvious difference was observed between the molecular weight properties of the kraft lignin and lignin esters, with the molecular weight distribution curves of the lignin esters showing a greater shift towards the high molecular weight region compared to that of the kraft lignin. Kraft lignin showed a number-average molecular weight $\left(M_{\mathrm{n}}\right)$ of $1400 \mathrm{~g} \cdot \mathrm{mol}^{-1}$, weight-average molecular weight $\left(M_{\mathrm{w}}\right)$ of 2300 $\mathrm{g} \cdot \mathrm{mol}^{-1}$, and polydispersity index $\left(\mathrm{PDI}=M_{\mathrm{w}} / M_{\mathrm{n}}\right)$ of 1.64 . After esterification, the lignin esters' molecular weight data are shown in Table 2. As predicted, a remarkable increase in the molecular weight of the lignin esters was observed after esterification, substantiating successful esterification. From the molecular weight data and distribution curves of E1 and E2, an increasing oleic acid dosage could not improve esterification. However, E3 and E5 
that were obtained by using a higher DBSA dosage showed a clearer increase in molecular weight than others. Their molecular weight data were analogous, except for E3 showing a higher weight-average molecular weight and wider polydispersity. These results indicated increasing DBSA dosage could improve esterification, but increasing reaction temperature had no effect on improving the degree of esterification, so esterification via using a higher DBSA dosage at room temperature is a good option.

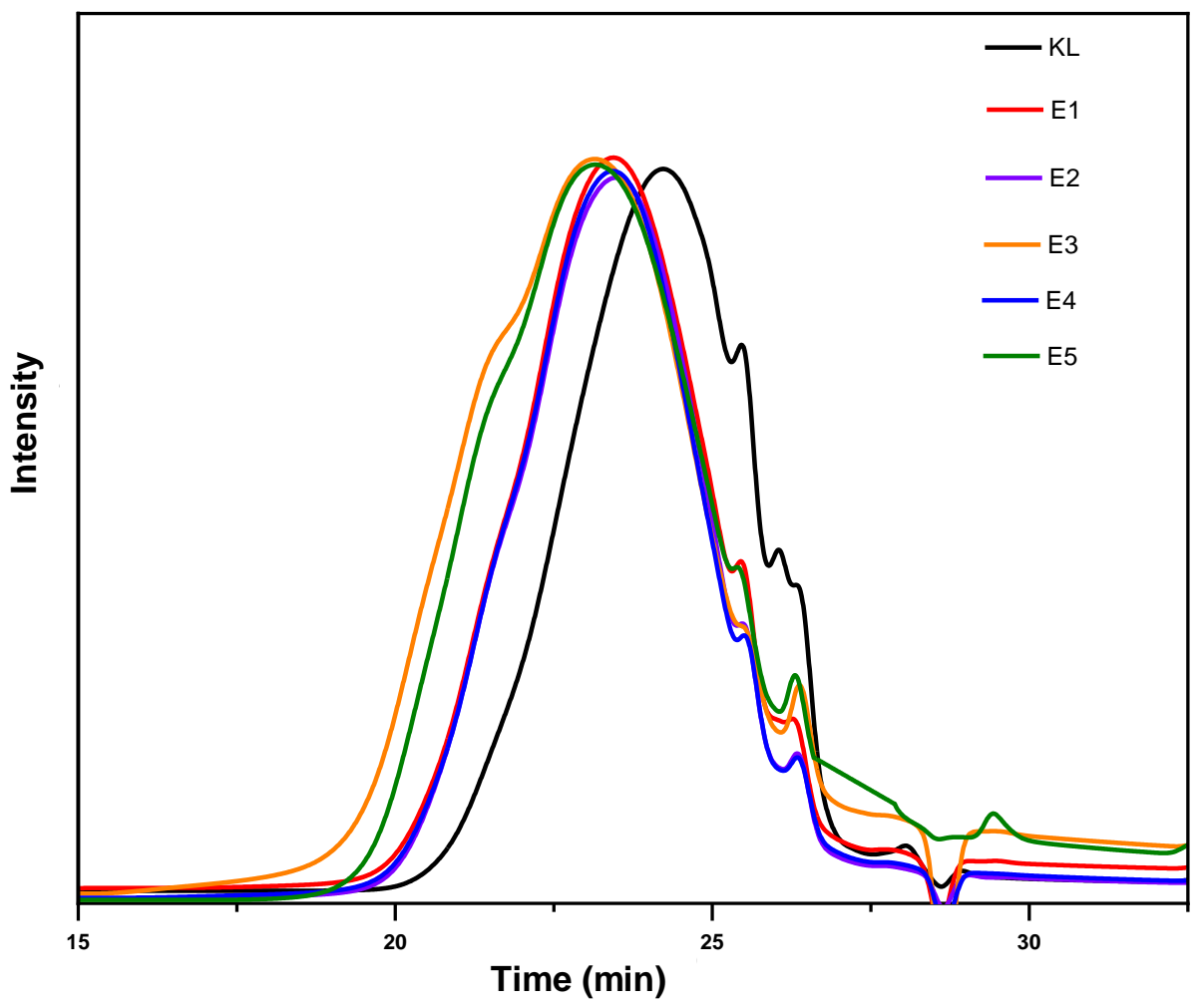

Fig. 4. Molecular weight distribution of kraft lignin $(\mathrm{KL})$ and lignin esters

Table 1. Molecular Weight and Particle Size of Kraft Lignin and Lignin Ester

\begin{tabular}{|c|c|c|c|c|c|}
\hline Sample & $\begin{array}{c}M_{\mathrm{n}} \\
\left(\mathrm{g} \cdot \mathrm{mol}^{-1}\right)\end{array}$ & $\begin{array}{c}M_{\mathrm{w}} \\
\left(\mathrm{g} \cdot \mathrm{mol}^{-1}\right)\end{array}$ & PDI & $\begin{array}{c}\text { Dv }(50)^{\mathrm{a}} \\
(\mu \mathrm{m})\end{array}$ & $\begin{array}{c}\mathrm{SSA}^{\mathrm{b}} \\
\left(\mathrm{m}^{2} / \mathrm{g}\right)\end{array}$ \\
\hline $\mathrm{KL}$ & 1400 & 2300 & 1.64 & 182.0 & 0.17 \\
\hline $\mathrm{E} 1$ & 1900 & 3300 & 1.74 & - & - \\
\hline $\mathrm{E} 2$ & 2100 & 3400 & 1.62 & - & - \\
\hline $\mathrm{E} 3$ & 2200 & 5100 & 2.32 & 2.4 & 3.78 \\
\hline $\mathrm{E} 4$ & 2000 & 3500 & 1.75 & - & - \\
\hline E5 & 2200 & 4400 & 2.00 & - & - \\
\hline $\begin{array}{l}\text { a Dv (50) represents the particle size corresponding to the volume distribution of 50\%; } \\
\text { b SSA is the abbreviation of specific surface area }\end{array}$
\end{tabular}

The FT-IR spectra (Fig. 5) of the kraft lignin and lignin esters were used to confirm the successful esterification via chemical structural analyses. The kraft lignin spectrum showed: an absorption at $3400 \mathrm{~cm}^{-1}$, corresponding to $\mathrm{O}-\mathrm{H}$ stretching vibrations of aliphatic and phenolic hydroxyl groups; absorptions at 2920 and $2850 \mathrm{~cm}^{-1}$, assigned to $\mathrm{C}-\mathrm{H}$ stretches of methyl and methylene groups; peaks at 1600, 1510, and $1425 \mathrm{~cm}^{-1}$, corresponding to skeletal vibrations of aromatic rings in the lignin structure; and peaks at 
1214 and $1113 \mathrm{~cm}^{-1}$, assigned to C-O stretching vibrations of syringyl rings in lignin (An et al. 2019). After esterification, all of the lignin esters spectra showed a slight decrease in absorption of O-H $\left(3400 \mathrm{~cm}^{-1}\right)$. Instead, a characteristic band at $1710 \mathrm{~cm}^{-1}$, assigned to the $\mathrm{C}=\mathrm{O}$ of the ester was clearly observed, providing convincing evidence for the successful esterification of lignin and oleic acid. Additionally, a clear increase in the absorption of C$\mathrm{H}$, from the methyl and methylene groups (2920 and $2850 \mathrm{~cm}^{-1}$ ), was attributed to the introduction of the long-aliphatic oleyl chain.

An increased signal between 1000 and $1300 \mathrm{~cm}^{-1}$, assigned to the expansion of the $\mathrm{C}-\mathrm{O}$ bonds in ester groups, was observed in spectra of all of lignin esters (Ibrahim et al. 2010). Compared with other spectra, the spectra of E3 and E5 showed a more obvious increase in this region. It indicated that higher DBSA dosages led to an improved degree of esterification in comparison with other reaction conditions. This may be due to the higher DBSA dosage that caused better dispersion of oleic acid, resulting in more adequate accessibility between the two substrates. Furthermore, the spectra of E3 and E5 showed a clear peak at $680 \mathrm{~cm}^{-1}$, assigned to $\mathrm{C}-\mathrm{H}$ in the double bond of the oleyl chain, which also confirmed the success of esterification (Van der Weerd et al. 2005) and also that higher DBSA dosage led to a more effective esterification. Concerning different oleic acid dosages, there was no clear difference between the spectra of E1 and E2. This signified that increasing oleic acid dosage had no obvious effect on the degree of esterification. Additionally, increasing reaction temperature from room temperature to $40{ }^{\circ} \mathrm{C}$ caused no difference in esterification, as shown in the spectra of E3 and E5, indicating that esterification at room temperature is a good option. These results agreed with the analyses of GPC, which showed that esterification (E3) using a higher DBSA dosage at room temperature was a good condition.

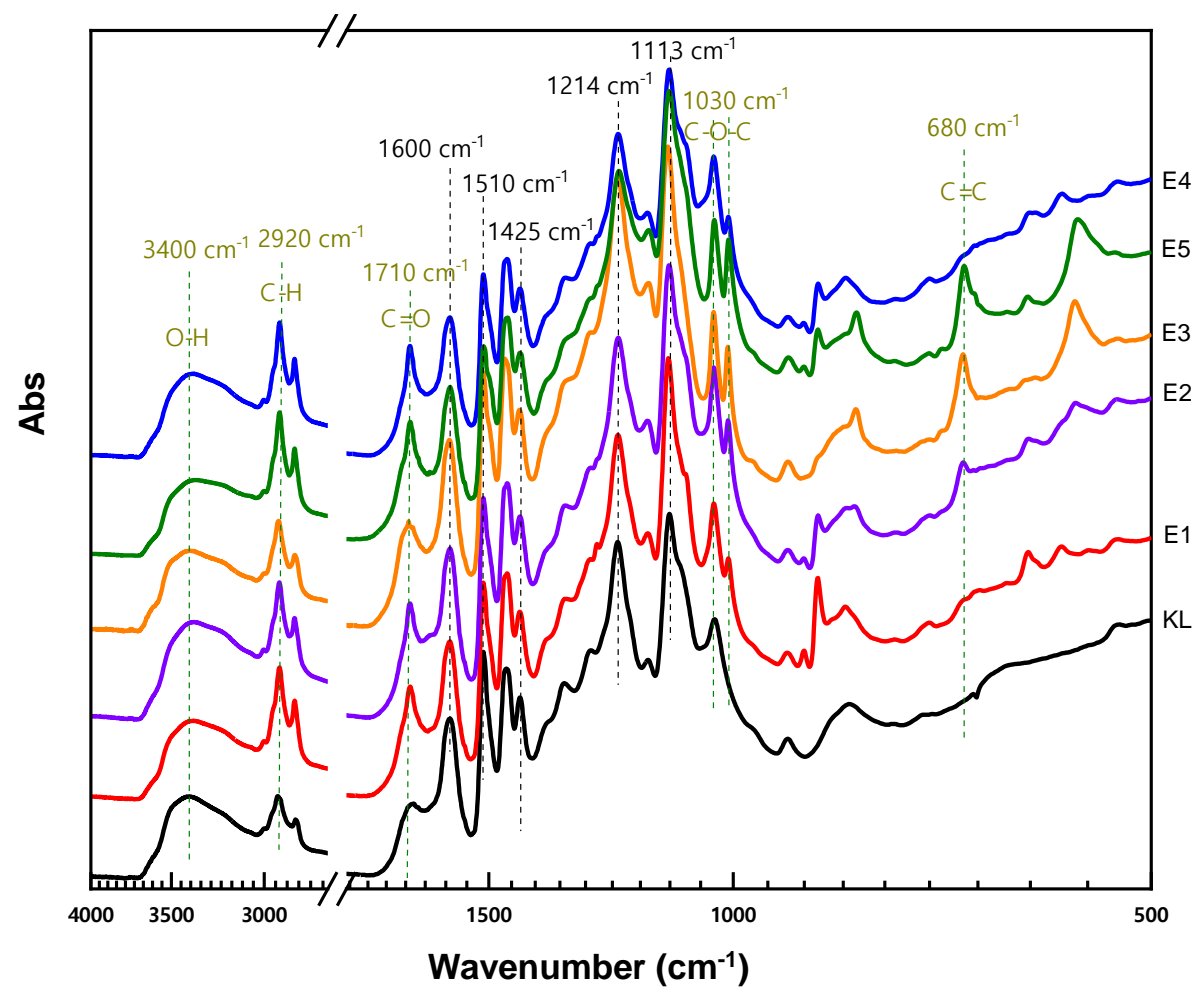

Fig. 5. FT-IR spectra of $\mathrm{KL}$ and lignin esters 
From the results of GPC and FT-IR, the lignin ester (E3) showed a competitive degree of esterification, so ${ }^{1} \mathrm{H}-\mathrm{NMR}$ spectroscopy of E3 was performed to further confirm the successful esterification by using surfactant-combined microreactors in water. As shown in Fig. 6, the ${ }^{1} \mathrm{H}-\mathrm{NMR}$ spectrum of E3 showed aromatic protons at 8.00 to 6.30 ppm, and methoxyl protons at 3.50 to $4.00 \mathrm{ppm}$. The two sharp signals at 3.35 and 2.50 ppm are related to the protons of water and DMSO- $d_{6}$, respectively (An et al. 2017). After esterification, the ${ }^{1} \mathrm{H}-\mathrm{NMR}$ spectrum of the E3 showed a characteristic peak at $2.18 \mathrm{ppm}$ (d), assigned to the protons in the $\alpha$-position of the ester linkage, which substantiated the successful esterification of lignin. Strong peaks at $5.30 \mathrm{ppm}$ were assigned to the $\mathrm{C}=\mathrm{C}$ protons (c) of the oleyl chain, while the protons (e) close to the double bond appeared as peaks at $1.98 \mathrm{ppm}$. The methyl (a) and methylene protons (b) of the oleyl chain give rise to signals at 0.86 and $1.25 \mathrm{ppm}$, respectively (Laurichesse et al. 2014; Xing et al. 2017). Therefore, the results of ${ }^{1} \mathrm{H}-\mathrm{NMR}$ were in good accordance with the FT-IR and GPC results, confirming successful esterification of lignin and oleic acid using surfactantcombined microreactors in water.

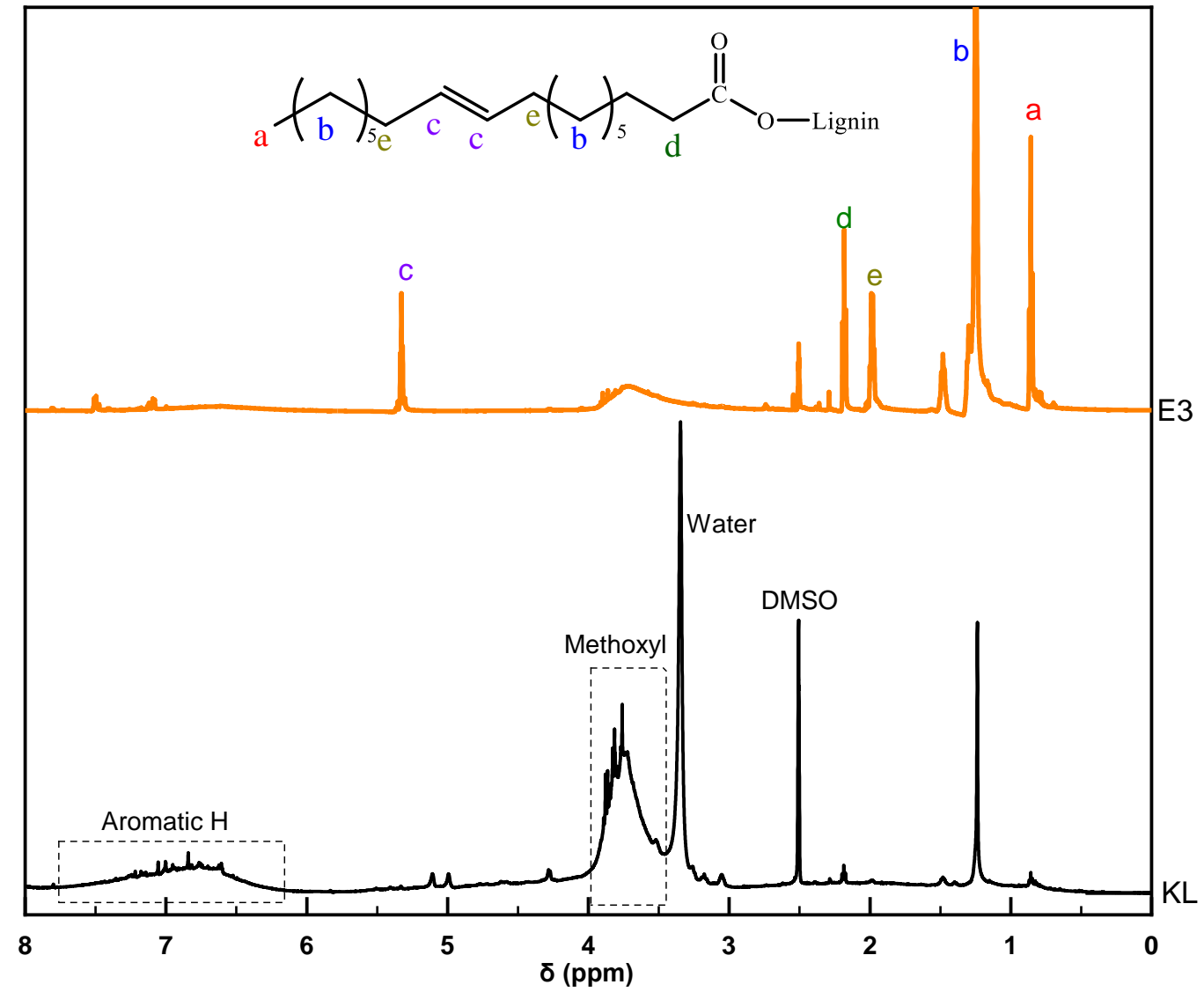

Fig. 6. ${ }^{1} \mathrm{H}$ NMR spectra of $\mathrm{KL}$ and lignin ester (E3)

\section{Particle Size Analyses of the Lignin Ester}

Solubilization of lignin in water was achieved using a high concentration of $\mathrm{TsOH}$ (above its CMC). After esterification, precipitation of lignin product was facilitated by diluting the reaction liquor below the $\mathrm{CMC}$ of $\mathrm{TsOH}$. Literature has reported using this micellization method to successfully prepare lignin nanoparticles (Chen et al. 2017). In the current study, the particle size of the lignin ester (E3) was determined using a particle size analyzer. After esterification, the lignin ester was precipitated by adding water to decrease 
the hydrotropicity of $\mathrm{TsOH}$. The particle size distribution curve (Fig. 7) illustrated a dramatic reduction in particle size for E3, with some lignin-ester particles falling in the nano-size range. The average particle size of the E3 was reduced to $2.4 \mu \mathrm{m}$ compared to that of the kraft lignin $(182.0 \mu \mathrm{m})$. Additionally, the specific surface area of E3 $\left(3.78 \mathrm{~m}^{2} / \mathrm{g}\right)$, which increased noticeably with the decrease in particle size (Table 1), was higher than that of the kraft lignin $\left(0.17 \mathrm{~m}^{2} / \mathrm{g}\right)$. These results suggest the possibility for lignin-ester nanoparticle preparation using surfactant-combined microreactors.

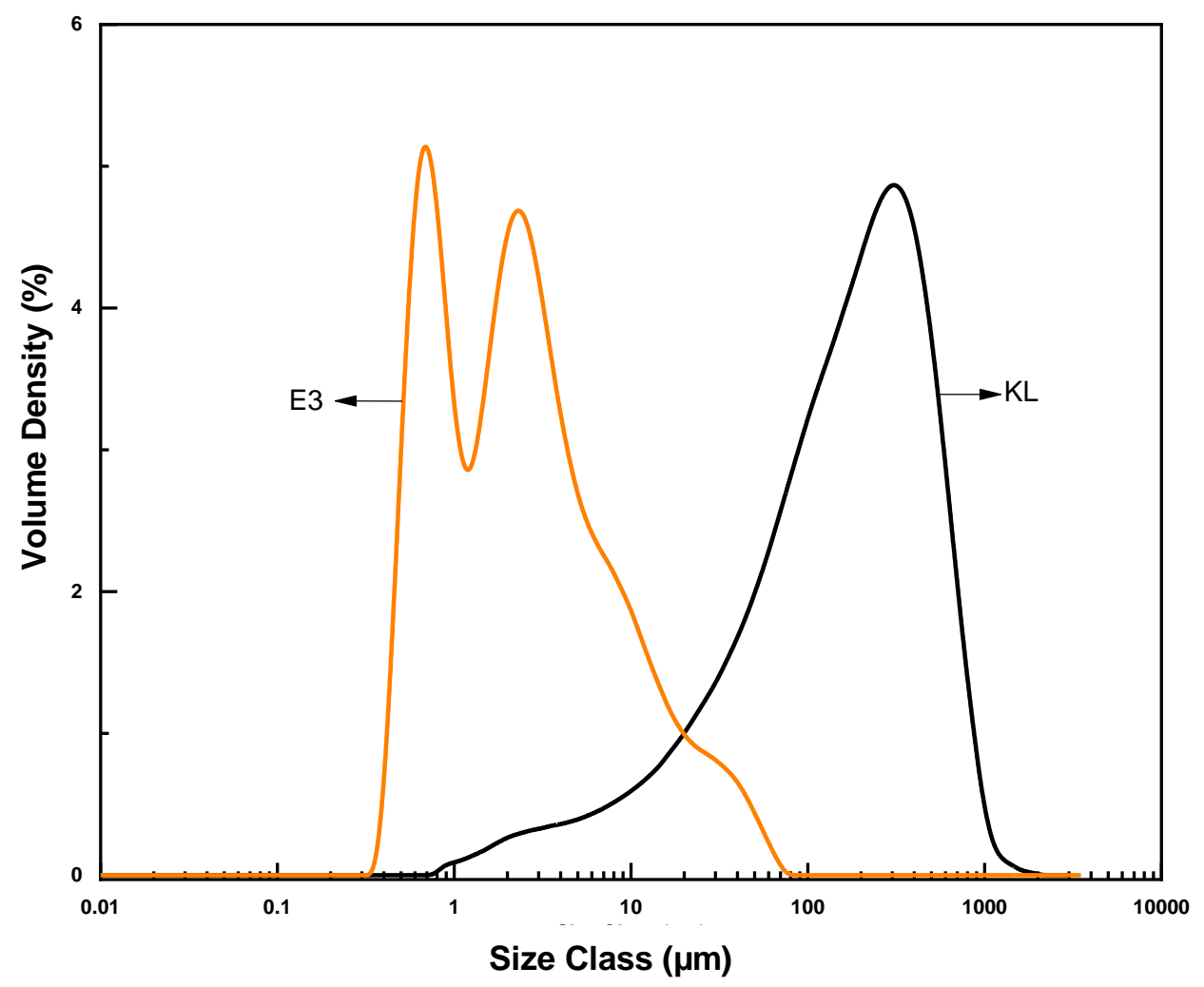

Fig. 7. Particle size distribution of kraft lignin and lignin ester (E3)

\section{Thermal Properties of the Lignin Ester}

Thermal properties of the kraft lignin and lignin ester (E3) were investigated by TGA and DSC. The TGA and derivative thermogravimetric (DTG) curves of the kraft lignin and E3 are presented in Fig. S1. The thermal properties, including the onset temperature (calculated at a weight loss of $5 \%, T_{5} \%$ ), maximum degradation temperature $\left(T_{\max }\right)$, and amount of residual char (char \%), are summarized in Table 2 . The minor weight loss observed below $130{ }^{\circ} \mathrm{C}$ for both lignin samples was attributed to the gradual evaporation of water. As shown, the weight loss of E3 due to water evaporation was lower than that of the kraft lignin, confirming that the lignin ester had a lower affinity for water and higher hydrophobicity (Gordobil et al. 2016). These results correspond to the contact angle analyses presented in the following section. For the kraft lignin, the main weight loss stage occurred in the temperature range between 205 to $600{ }^{\circ} \mathrm{C}$, with maximum degradation at $345{ }^{\circ} \mathrm{C}$. The thermal parameter $T_{5 \%}$ values for the kraft lignin and E3 remained almost unchanged $\left(\approx 205^{\circ} \mathrm{C}\right)$. However, according to the DTG curves, E3 showed a two-step degradation process, distinctly different from that of the kraft lignin. As shown in the TGA and DTG curves of the E3, the first degradation process occurred in the temperature range 
between 205 to $320^{\circ} \mathrm{C}$, with maximum degradation at $250{ }^{\circ} \mathrm{C}$, while a second degradation process occurred in the temperature range between 320 to $600{ }^{\circ} \mathrm{C}$, with a maximum degradation at $385{ }^{\circ} \mathrm{C}$. Previous research has confirmed that introduction of a long-oleyl chain into the lignin macromolecule creates this two-step degradation (Xing et al. 2017). The first degradation phase is associated with the degradation of hydrocarbon chains (mainly involving the introduced long-aliphatic chain), while the second degradation phase may present the degradation of the lignin skeleton. In addition, the value of residual char for E3 decreased to $34.8 \%$, compared to $43.2 \%$ for the kraft lignin. Therefore, the lignin ester obtained in this work has similar thermal properties to lignin esters obtained using acyl chlorides and organic solvents (Gordobil et al. 2016; Xing et al. 2017).

Table 2. Thermal Properties of Kraft Lignin and Lignin Ester (E3)

\begin{tabular}{|c|c|c|c|c|c|}
\hline Sample & $T_{5 \%}\left({ }^{\circ} \mathrm{C}\right)$ & \multirow{2}{*}{\multicolumn{2}{|c|}{$\frac{T_{\max }\left({ }^{\circ} \mathrm{C}\right)}{345}$}} & Char (\%) & $T_{g}\left({ }^{\circ} \mathrm{C}\right)$ \\
\hline Kraft lignin & 205 & & & 43.2 & 124.4 \\
\hline E3 & 205 & 250 & 385 & 34.8 & 108.1 \\
\hline
\end{tabular}

Differential scanning calorimetry is commonly used to define the $T_{\mathrm{g}}$ of polymers. Figure S2 shows the DSC curves of the kraft lignin and lignin ester (E3). Kraft lignin is a rigid, condensed aromatic molecule, which possesses strong hydrogen bonding intermolecular interactions caused by its hydroxyl groups. This leads to poor thermal mobility and thermoplasticity (Koivu et al. 2016). As shown in Table 2, the $T_{\mathrm{g}}$ of the kraft lignin was relatively high $\left(124.4^{\circ} \mathrm{C}\right.$ ), which agrees with literature data (Cui et al. 2013; Hulin et al. 2015). However, the curve of the E3 showed a clear and low $T_{\mathrm{g}}$ at $108.1{ }^{\circ} \mathrm{C}$, which corresponds to the literature (Koivu et al. 2016). Thus, a considerable reduction in the $T_{\mathrm{g}}$ of E3 compared to that of the kraft lignin was observed. After esterification, hydroxyl groups were substituted with ester groups, resulting in reduced hydrogen bonding and introduction of a long, flexible aliphatic chain. This lowered the glass transition point and improved the thermoplasticity of the lignin (Dehne et al. 2016).

\section{Hydrophobic Properties of the Lignin Ester}

The contact angles of liquids on solid surfaces provide direct information about the wetting behaviors of the surfaces. The contact angles with water of the kraft lignin and lignin ester (E3) were measured to analyze changes in lignin hydrophobicity. A remarkable difference between the contact angle of the kraft lignin and E3 can be seen in Fig. 8. With increased time, the contact angle of the kraft lignin sharply decreased compared to that of the E3. At $2 \mathrm{~s}$, the contact angle of the kraft lignin was $30.1^{\circ}$, which was much lower than that of E3 $\left(109.8^{\circ}\right)$. After esterification, the contact angle of E3 was higher and more stable than that of the kraft lignin. This indicated the wetting properties of the lignin ester against water were remarkably improved, and that esterification is an effective method to endue lignin with good hydrophobicity. 

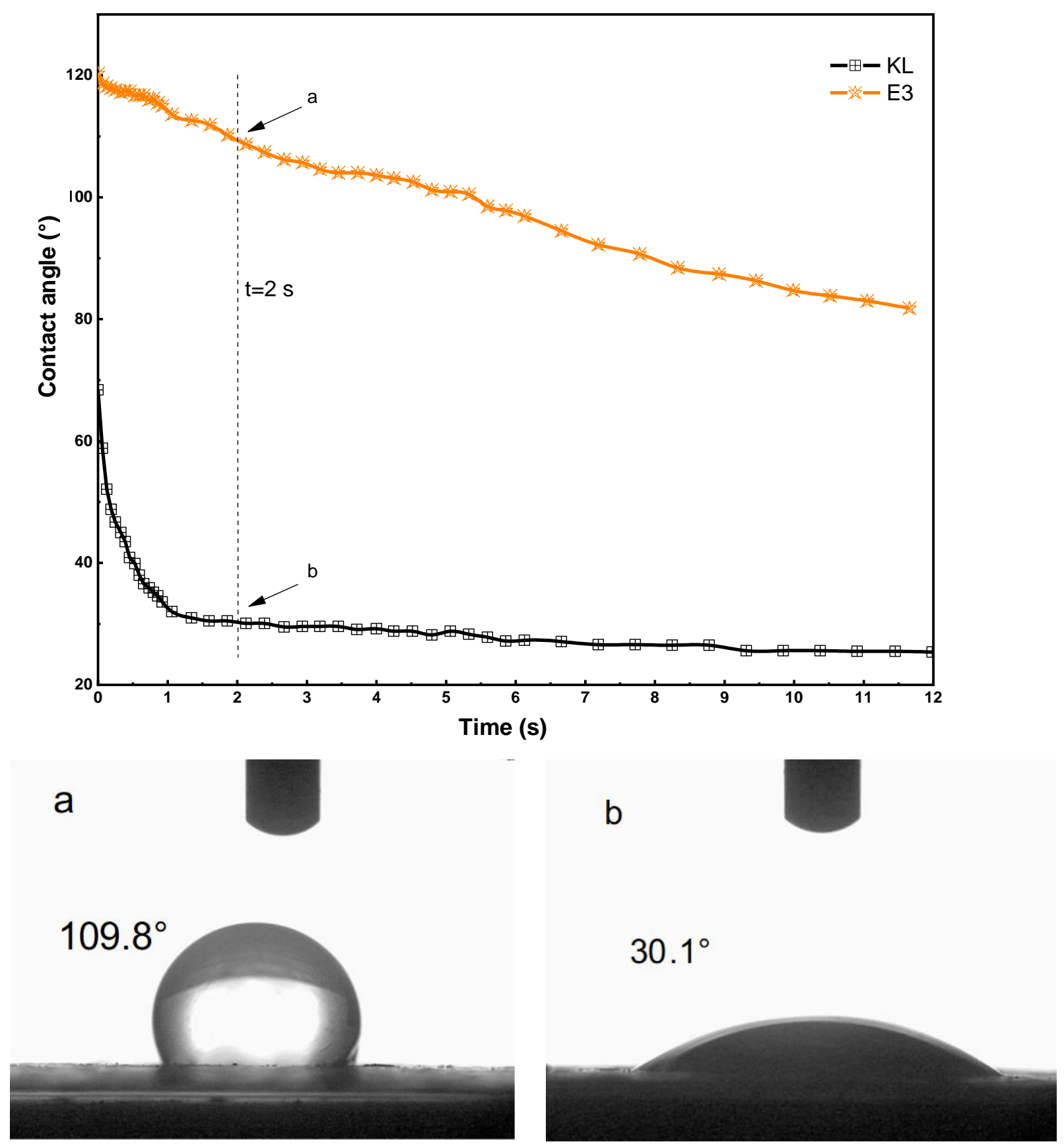

Fig. 8. Contact angles of $K L$ and lignin ester (E3) (Images were recorded at $2 \mathrm{~s}$ )

\section{CONCLUSIONS}

1. A green method for esterification of kraft lignin and oleic acid in water at room temperature was successfully achieved.

2. Surfactant-combined microreactors were formed using TsOH/DBSA, which were able to solubilize kraft lignin and disperse oleic acid. 
3. Increasing oleic acid dosage had no effect on improving the degree of esterification, instead, using a higher DBSA dosage at room temperature is a good option for esterification.

4. Structural characterization confirmed successful esterification of kraft lignin with oleic acid, and improved thermoplasticity and hydrophobicity of the lignin ester.

5. The PSA results suggested the possibility for preparation of lignin-ester nanoparticles using a micellization method.

\section{ACKNOWLEDGMENTS}

This work was supported by the Basic Science Research Program through the National Research Foundation of Korea (NRF) funded by the Ministry of Education (No. 2018R1A6A1A0325582). The authors also acknowledge The Central Laboratory of Kangwon National University, Kangwon National University (Chuncheon, South Korea) for ${ }^{1} \mathrm{H}$ NMR analysis.

\section{REFERENCES CITED}

An, L., Si, C., Wang, G., Sui, W., and Tao, Z. (2019). "Enhancing the solubility and antioxidant activity of high-molecular-weight lignin by moderate depolymerization via in situ ethanol/acid catalysis," Industrial Crops and Products 128, 177-185. DOI: 10.1016/j.indcrop.2018.11.009

An, L., Wang, G., Jia, H., Liu, C., Sui, W., and Si, C. (2017). "Fractionation of enzymatic hydrolysis lignin by sequential extraction for enhancing antioxidant performance,"

International Journal of Biological Macromolecules 99, 674-681. DOI: 10.1016/j.ijbiomac.2017.03.015

Baile, M., Chou, Y. J., and Saam, J. C. (1990). "Direct polyesterifcation in aqueous emulsion," Polymer Bulletin 23(3), 251-257. DOI: 10.1007/BF01032438

Chen, L., Dou, J., Ma, Q., Li, N., Wu, R., Bian, H., Yelle, D. J., Vuorinen, T., Fu, S., Pan, X., et al. (2017). "Rapid and near-complete dissolution of wood lignin at $\leq 80{ }^{\circ} \mathrm{C}$ by a recyclable acid hydrotrope," Science Advances 3(9), e1701735. DOI: 10.1126/sciadv. 1701735

Cui, C., Sadeghifar, H., Sen, S., and Argyropoulos, D. S. (2013). "Toward thermoplastic lignin polymers; Part II: Thermal \& polymer characteristics of kraft lignin \& derivatives," BioResources 8(1), 864-886. DOI: 10.15376/biores.8.1.864-886

Dehne, L., Babarro, C. V., Saake, B., and Schwarz, K. U. (2016). "Influence of lignin source and esterification on properties of lignin-polyethylene blends," Industrial Crops and Products 86, 320-328. DOI: 10.1016/j.indcrop.2016.04.005

Gordobil, O., Herrera, R., Llano Ponte, R., and Labidi, J. (2017). "Esterified organosolv lignin as hydrophobic agent for use on wood products," Progress in Organic Coatings 103, 143-151. DOI: 10.1016/j.porgcoat.2016.10.030

Gordobil, O., Robles, E., Egüés, I., and Labidi, J. (2016). "Lignin-ester derivatives as novel thermoplastic materials," RSC Advances 6(90), 86909-86917. DOI:

10.1039/C6RA20238A 
Hulin, L., Husson, E., Bonnet, J. P., Stevanovic, T., and Sarazin, C. (2015). "Enzymatic transesterification of kraft lignin with long acyl chains in ionic liquids," Molecules 20(9), 16334-16353. DOI: 10.3390/molecules200916334

Hult, E.-L., Koivu, K., Asikkala, J., Ropponen, J., Wrigstedt, P., Sipilä, J., and PoppiusLevlin, K. (2013). "Esterified lignin coating as water vapor and oxygen barrier for fiber-based packaging," Holzforschung 67(8), 899-905. DOI: 10.1515/hf-2012-0214

Ibrahim, M. N. M., Ahmed Haras, M. R., Sipaut, C. S., Aboul Enein, H. Y., and Mohamed, A. A. (2010). "Preparation and characterization of a newly water soluble lignin graft copolymer from oil palm lignocellulosic waste," Carbohydrate Polymers 80(4), 1102-1110. DOI: 10.1016/j.carbpol.2010.01.030

Kai, D., Tan, M. J., Chee, P. L., Chua, Y. K., Yap, Y. L., and Loh, X. J. (2016). "Towards lignin-based functional materials in a sustainable world," Green Chemistry 18(5), 1175-1200. DOI: 10.1039/C5GC02616D

Koivu, K. A., Sadeghifar, H., Nousiainen, P. A., Argyropoulos, D. S., and Sipilä, J. (2016). "Effect of fatty acid esterification on the thermal properties of softwood kraft lignin," ACS Sustainable Chemistry \& Engineering 4(10), 5238-5247. DOI: 10.1021/acssuschemeng.6b01048

Laurichesse, S., Huillet, C., and Avérous, L. (2014). "Original polyols based on organosolv lignin and fatty acids: New bio-based building blocks for segmented polyurethane synthesis," Green Chemistry 16(8), 3958-3970. DOI: 10.1039/C4GC00596A

Lewis, H., Brauns, F., Buchanan, M., and Brookbank, E. (1943). "Lignin esters of monoand dibasic aliphatic acids," Industrial \& Engineering Chemistry 35(10), 1113-1117. DOI: $10.1021 / \mathrm{ie} 50406 \mathrm{a} 020$

Luo, S., Cao, J., and McDonald, A. G. (2017). "Esterification of industrial lignin and its effect on the resulting poly(3-hydroxybutyrate-co-3-hydroxyvalerate) or polypropylene blends," Industrial Crops and Products 97, 281-291. DOI: 10.1016/j.indcrop.2016.12.024

Manabe, K., Iimura, S., Sun, X. M., and Kobayashi, S. (2002b). "Dehydration reactions in water. Brønsted acid- surfactant-combined catalyst for ester, ether, thioether, and dithioacetal formation in water," Journal of the American Chemical Society 124(40), 11971-11978. DOI: 10.1021/ja026241j

Manabe, K., and Kobayashi, S. (2002a). "Dehydrative esterification of carboxylic acids with alcohols catalyzed by polymer-supported sulfonic acids in water," Advanced Synthesis \& Catalysis 344(3-4), 270-273. DOI: 10.1002/16154169(200206)344:3/4<270::AID-ADSC270>3.0.CO;2-7

Pawar, S. N., Venditti, R. A., Jameel, H., Chang, H. M., and Ayoub, A. (2016). "Engineering physical and chemical properties of softwood kraft lignin by fatty acid substitution," Industrial Crops and Products 89, 128-134. DOI:

10.1016/j.indcrop.2016.04.070

Schutyser, W., Renders, T., Van den Bosch, S., Koelewijn, S. F., Beckham, G., and Sels, B. F. (2018). "Chemicals from lignin: An interplay of lignocellulose fractionation, depolymerisation, and upgrading," Chemical Society Reviews 47(3), 852-908. DOI: 10.1039/C7CS00566K

Seo, J. H., Jeong, H., Lee, H. W., Choi, C. S., Bae, J. H., Lee, S. M., and Kim, Y. S. (2019). "Characterization of solvent-fractionated lignins from woody biomass treated via supercritical water oxidation," Bioresource Technology 275, 368-374. DOI: 10.1016/j.biortech.2018.12.076 
Ten, E., and Wilfred V. (2015). "Recent developments in polymers derived from industrial lignin," Journal of Applied Polymer Science 132(24), 42069. DOI: 10.1002/app.42069

Teramoto, Y., Lee, S. H., and Endo, T. (2009). "Phase structure and mechanical property of blends of organosolv lignin alkyl esters with poly( $\varepsilon$-caprolactone)," Polymer Journal 41(3), 219. DOI: 10.1295/polymj.PJ2008301

Thielemans, W., and Wool, R. P. (2005). "Lignin esters for use in unsaturated thermosets: Lignin modification and solubility modeling," Biomacromolecules 6(4), 1895-1905. DOI: 10.1021/bm0500345

Van Dam, J. E., De Klerk-Engels, B., Struik, P. C., and Rabbinge, R. (2005). "Securing renewable resource supplies for changing market demands in a bio-based economy," Industrial Crops and Products 21(1), 129-144. DOI: 10.1016/j.indcrop.2004.02.003

Van der Weerd, J., Van Loon, A., and Boon, J. J. (2005). "FTIR studies of the effects of pigments on the aging of oil," Studies in Conservation 50(1), 3-22. DOI: 10.1179/sic.2005.50.1.3

Wang, C., Kelley, S. S., and Venditti, R. A. (2016). "Lignin-based thermoplastic materials," ChemSusChem 9(8), 770-783. DOI: 10.1002/cssc.201501531

Wang, G., Liu, X., Yang, B., Si, C., Parvez, A. M., Jang, J., and Ni, Y. (2019). "Using green $\gamma$-valerolactone/water solvent to decrease lignin heterogeneity by gradient precipitation," ACS Sustainable Chemistry \& Engineering 7(11), 10112-10120. DOI: 10.1021/acssuschemeng.9b01641

Wu, M., Pang, J., Lu, F., Zhang, X., Che, L., Xu, F., and Sun, R. (2013). "Application of new expansion pretreatment method on agricultural waste. Part I: Influence of pretreatment on the properties of lignin," Industrial Crops and Products 50, 887-895. DOI: 10.1016/j.indcrop.2013.08.047

Xing, Q., Ruch, D., Dubois, P., Wu, L., and Wang, W. (2017). "Biodegradable and highperformance poly (butylene adipate-co-terephthalate)-lignin UV-blocking films," ACS Sustainable Chemistry \& Engineering 5(11), 10342-10351. DOI: 10.1021/acssuschemeng.7b02370

Zhao, X., Zhang, Y., Hu, H., Huang, Z., Qin, Y., Shen, F., Huang, A., and Feng, Z. (2019). "Effect of lignin esters on improving the thermal properties of poly(vinyl chloride)," Journal of Applied Polymer Science 136(11), Article ID 47176. DOI: 10.1002/app. 47176

Zhou, S., Liu, L., Wang, B., Xu, F., and Sun, R. (2012). "Microwave-enhanced extraction of lignin from birch in formic acid: Structural characterization and antioxidant activity study," Process Biochemistry 47(12), 1799-1806. DOI: 10.1016/j.procbio.2012.06.006

Article submitted: September 11, 2019; Peer review completed: October 19, 2019: Revised version received: October 27, 2019; Accepted: November 1, 2019; Published: November $8,2019$.

DOI: $10.15376 /$ biores. $15.1 .89-104$ 


\section{SUPPLEMENTARY INFORMATION}

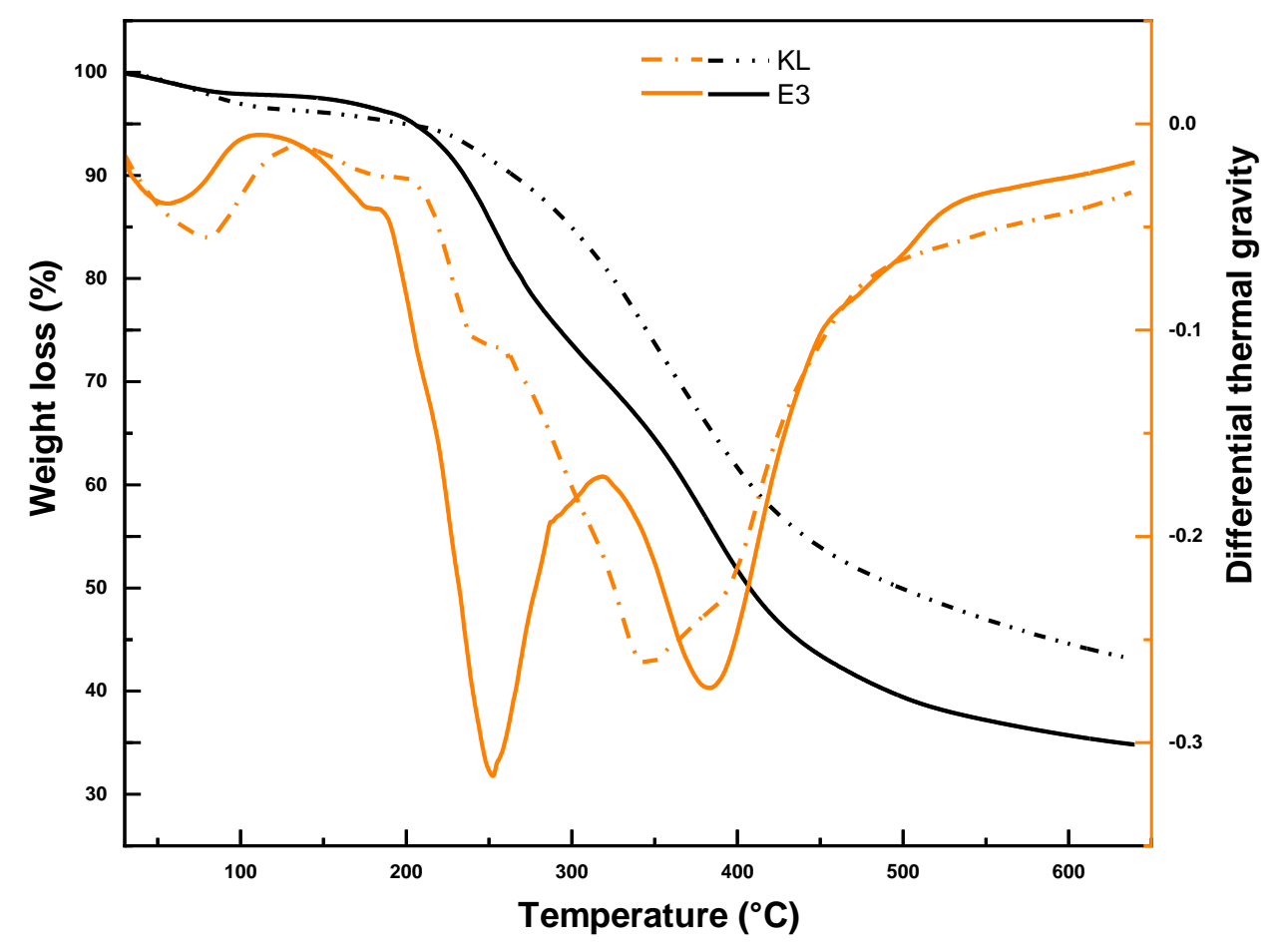

Fig. S1. TGA and DTG curves of KL and lignin ester (E3)

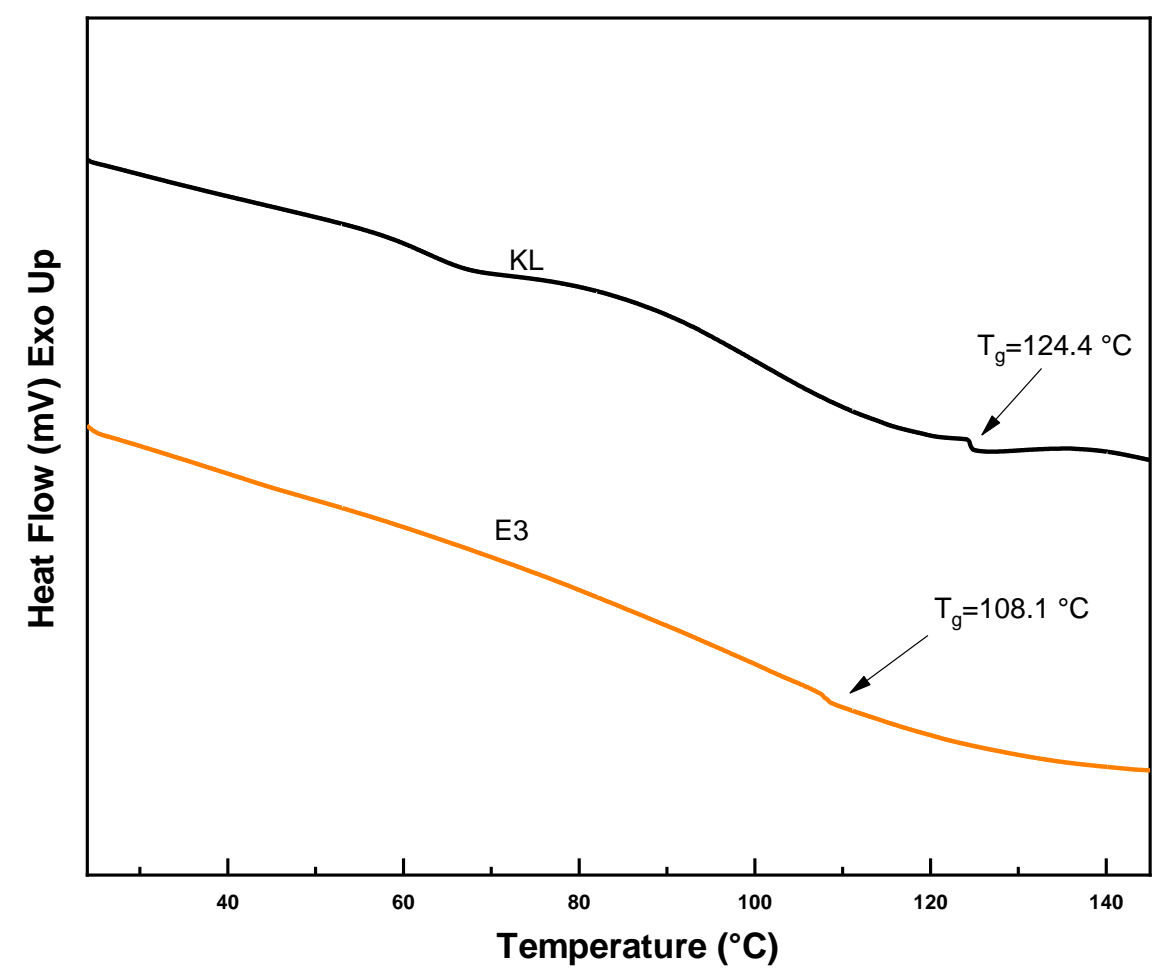

Fig. S2. DSC curves of $\mathrm{KL}$ and lignin ester (E3) 